Ärztliche Erfahrung beschränkt sich nicht auf medizinisches Fachwissen. Sie entsteht auch aus den mehr oder minder alltäglichen, heiter, ärgerlich oder nachdenklich stimmenden Erlebnissen mit Patienten, Kollegen und Mitarbeitern. Senden Sie uns Ihre Geschichte an: Brigitte.Moreano@springer.com. Für jeden veröffentlichten Text erhalten Sie bis zu 100 Euro.

\title{
Eine „rücksichtsvolle“ alte Dame
}

- Es wurde stockdunkel, als ich den Zündschlüssel meines Autos abzog und damit das letzte Licht erlosch. In unserem kleinen Dörfchen wurde zwischen ein und fünf Uhr nachts immer die Straßenbeleuchtung ausgeschaltet und ich kam gerade von meinem letzten angeforderten Hausbesuch im Notdienst nach Hause. Alles war ruhig, meine Kinder lagen tief und fest schlafend in ihren Betten.

Während ich noch überlegte, ob ich auch gleich ins Bett gehen oder erst meinen knurrenden Magen beruhigen sollte, klingelte die Zentrale erneut an. Eine alte Dame hatte wegen plötzlicher Rückenschmerzen und Atemproblemen den Notdienst angerufen. Ich hatte erst letzte Woche in meiner Praxis eine Frau mit einer Lungenembolie gesehen, also schob ich mir schnell ein Stück Schokolade in den Mund, während ich auf der Karte nachsah, wo sie wohnte, dann fuhr ich noch mal los.

Am Ziel angekommen, öffnete mir eine freundliche alte Frau, die sehr erleichtert war, dass ich kam. Sie schilderte mir, dass sie schon seit einiger Zeit unter Rückenschmerzen leide. Sie habe schon drei Thomapyrin genommen, ohne dass es ihr besser gehe. Sie habe heute "große Wäsche" gemacht, habe nun zum Abend so schlimme Schmerzen, dass sie nicht mehr richtig Luft holen könne. Auch Hinlegen gehe gar nicht. So könne sie nicht schlafen.

Bei der Untersuchung der 82-Jährigen fand sich eine deutliche Skoliose, eine stark verminderter Becken-Rippenbogenabstand, die LWS war relativ unbeweglich, es gab aber weder einen umschriebenen Klopf-, Druck- oder Stauchungsschmerz der

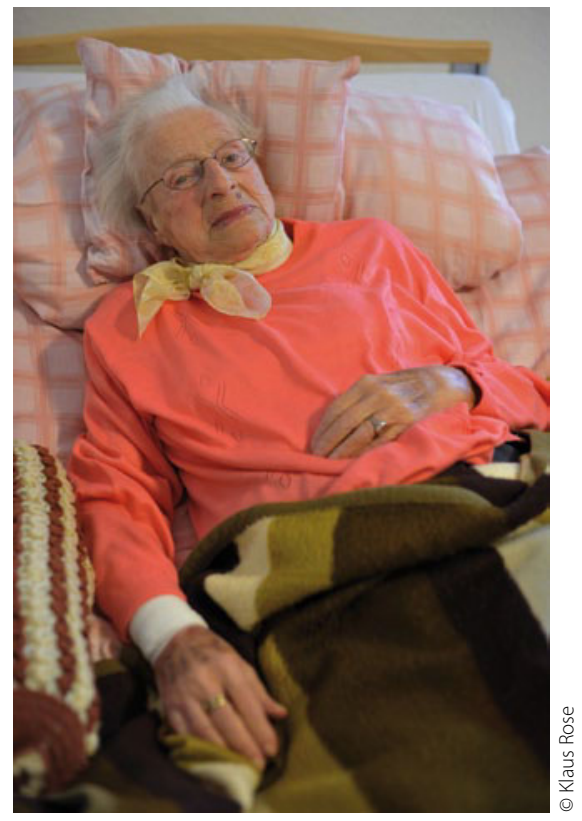

Die Angehörigen brauchen ihren Nachtschlaf - und Frau Doktor nicht?

Wirbelsäule noch neurologische Ausfälle. Die Lunge war frei, die HT leise, arrhythmisch, der Blutdruck war aktuell 120/75. Auf dem Medikamentenplan fand sich neben Ramipril/HCT, Amlodipin, Ca, Vit D und Alendronsäure auch Markumar. Im Ausweis war bei der letzten Kontrolle vor drei Tagen ein fast idealer Wert von 27 eingetragen, eine Dosisänderung hatte nicht stattgefunden.

Also musste ich nur überlegen, wie dem offensichtlich vertebragenen Schmerz am besten beizukommen war. In der Hausapotheke fanden sich Tramadoltropfen, „die hatte der Hausarzt mal verschrieben", aber die werde sie nicht nehmen, davon sei ihr mal so schwindelig geworden und schließlich habe sie schon eine künstliche Hüfte, weil sie letztes Jahr gestürzt war. Ob ich ihr denn nichts spritzen könne? Deshalb habe sie doch angerufen.

Nur ein Rezept? Mitten in der Nacht? Geduldig erklärte ich der Guten, dass die einzigen Spritzen, die hilfreich wären 95 (eine lokale Infiltration), bei ihr nicht in Frage kämen, wegen der "Blutverdünnung", und dass überhaupt Tabletten genauso gut wirkten. (Zwar hatte ich kurz erwogen, ihr Metamizol als Kurzinfusion zu geben, aber da der Blutdruck schon so niedrig war, wollte ich das dann doch nicht riskieren.) So schrieb ich es auf ein Rezept und wollte mich nach dem Überreichen verabschieden, um selber noch ein bisschen Schlaf zu bekommen. Aber die alte Dame war nicht zufrieden.

Ob ich denn keine Tabletten mithätte? Was solle sie denn mitten in der Nacht mit einem Rezept anfangen? Also rief ich noch mal die Notdienstzentrale an, um nachzufragen, welche Apotheke heute Nacht Bereitschaft hatte, und erklärte ihr, dass sie nur jemanden finden müsse, der die Tabletten für sie hole. Nun meinte sie aber ganz selbstlos, dann eben bis zum Morgen warten zu wollen, schließlich seien sowohl ihre Nachbarn wie auch ihre Kinder berufstätig und brauchten ihren Nachtschlaf.

Noch ganz gerührt von so viel Rücksichtsnahme sank auch ich eine halbe Stunde später müde in mein Bett.

Dr. MED. ANDREA LINSEL, LÜNEBURG • 